\title{
TOXICOLOGY IN MEDICAL PRACTICE- TIME FOR REVOLUTIONARY CHANGE
}

The toxicology has long been the neglected topic and dealt with less importance. But the burdon of the disease and the morbidity and mortality is biggest in this respect. According to Directorate General of Health service of Bangladesh health bulletin 2017 report the number of poisoning is $1.6 \%, 6.9 \%$ and $5.9 \%$ among all causes of morbidity in primary,secondary and tertiary health care centers. In tertiary care centre the poisoning related mortality is $1.97 \%$, in district hospital it is $3.28 \%$ while in primary health care centre it is $4.9 \%$ among ages more than $5 \mathrm{yrs}$ with national trends of mortality of $2.83 \%{ }^{1}$.

It has been observed that the incidence of poisoning has been on increase gradually since 1988 to 1996 except in the year 1990 and $1993^{2}$ Number of chemicals use in industry, agriculture and medical profession is rising faster than it was anticipated. Consequently misuses of pesticides, chemicals (harpic, nail polish, rat killer) drugs (sedatives) have been observed. Exposure to chemicals can cause acute intoxication and chronic poisoning. Acute exposure is a single contact that lasts for second, minutes or hours.

Pesticide, copper sulphate, kerosene and poisoning by unknown sedative substances for stupefying purpose and with occasional reports of methanol, aluminum phosphide poisoning and puffer fish intoxication are often faced by the different level of Physicians $^{3}$. These cases need special care and medication. Small scale psychiatric analysis of deliberate self poisoning victims could not detect high proportion of major psychiatric illness among the poisoned cases ${ }^{4}$. Easy availability of cheap pesticide within the household could contribute to use them as agent of deliberate self harm.

Snake bite is an important public health problem in Bangladesh. An old study estimated incidence is about 8000 per year with 20\% deaths. The well designed countrywide survey revealed the estimated incidence density of snake bite is $623.4 / 100,000$ person years (95\% C I 513.4-789.2/100,000 person years ${ }^{5}$. Bangladesh is a flood prone country; During the monsoons and post monsoon seasons, people who are affected by snake bite has exceeded that of diarrhoea. A report from director general's office explored that, snake bite was one of the top most cause of death during flood. Global warming also likely to change the bio-diversity of snakes in this region. More bite with different variety of snakes will suppose to happen in coming future.

Among the affected snake bite patients, the number that actually die from these bites are significant. Due to strong belief of the public on traditional treatment by 'Ozhas' and lack of awareness on scientific treatment by the medical profession, the patients do not get appropriate treatment. In our country, most of the deaths due to snake bite occur at home or en route to hospital. Hospital treatment based on advanced scientific knowledge is now practiced in many parts of the world. The poisoning cases including snake bite is still not appropriately addressed in health policy and the medical professionals are managing the cases with independent views rather uniform comprehensive approach.

There is also dilemma in diagnosisng both poisoning and snake bite cases in clinical setting. The clinical syndromic approach is justified in the setting of unsure medical history and lack of diagnostic facility. The advanced world is hedding towards molecular toxicology while we are still not having consistent laboratory for toxicological analysis. Even after the death, where the medicolegal issue become a big concern, the diagnostic facility of autopsy is not uniform countrywide. There is also lack of all antidotes in all health tiers in Bangladesh.Capacity development including trained physicians to deal in toxicology is still inappropriate. el related i.e. stupefying poisoning. The existing medical education is still not uptodate with current concept of toxicology ${ }^{6}$. Provision for necessary supply of logistics at appropriate level of care is required. In depth studies related to various aspects of poisoning by different agents could be conducted for further improvement of management. The snake bite with enormous venomics subject has been always neglected and venom characteristics of snakes and 
its effect in human has no attenttion at all.There is no labotratory set up which can uses appropraite scientic evenue for diagnosis of snake bite in Bangladesh.The venom production and its use to prepare antivenom or other uses in medical science is an advancement in this century while we remain in ancestry of managing the cases with existing antivenom from India. The WHO has set up standard to produce antivenom which should be country specific and species specific for its own land.

WHO recently declared the snake bite as the neglected tropical disease and gives importance to reduce the mortality and morbidity globally. The roadmap for this public health importance is now the priority which is on the process of preparing including different strategies. The noncommmunicable disease of DGHS has also take early appropriate plan to mitigate the problem of snake bite in Bangladesh. A snake venom research project has developed in Chittagong Medical College Hospital premise which is doing research on venom, capturing snakes and extracting venoms of difdferent species, piloting registry of snake bite, giving training of physicians and health care providers, creating awarenesss program in snake bite prone area and exploring venom standard for Bangladesh.

Poisoning and snake bite is one of the commonest causes of hospital admission in Bangladesh. Creation of evidence by recording cases of poisoning and snake bite is crucial to see the extent of the problem ${ }^{6}$. There should be some revolutionary changes needed to change the scenario of neglected status of these two public health related medical problem. These changes needed in government policy, in multi ministry interaction, public private relationship, specific disease wise agenda with strategy with appropriate implementation in health sectors of all necessary plan to mitigate the problem of poisoning and snake bite in Bangladesh. The 2030 vision of sustainable development goal is the ultimate goal in global health program and to achieve that, there should be revolutionary changes in these sectors needed and steps are to be started immediately.

\section{Md Robed Amin', Quazi Tarikul Islam²}

1. Associate Professor of Medicine, Dhaka Medical College

2. Professor of Medicine. Popular Medical College

\section{References:}

1. Health Bulletin 2017, Management Information System Directorate General of Health Services, Government of the People's Republic of Bangladesh Ministry of Health and Family Welfare, pp74-79

2. Bari MA, Faiz MA (2003) A Programme to establish a Poison information centre in Bangladesh. Final Report

3. Md Robed Amin, Ariful Basher, Abdus Sattar, Anisul Awal, Mustaque Rahim Sapan, Aniruddha Ghose and MA Faiz. Baseline Survey on Cases of Poisoning and its Outcome in Bangladesh. Open Acc J of Toxicol. 2017; 2(2):001-006, OAJT.MS.ID.555583

4. Rahman MM .Clinical pattern of acute poisoning in medical units of DMCH. (1994) JDMC 3(1): 15.5 .

5. Ridwanur Rahman, M. Abul Faiz, Shahjada Selim, Bayzidur Rahman, Ariful Basher, Alison Jones et al. Annual Incidence of Snake Bite in Rural Bangladesh. PLoS Neg1 Trop Dis 4(10): e860. doi:10.1371/journal.pntd.0000860

6. Faiz MA (2002) Nationwide Survey of pattern of Poisoning in Bangladesh. 